\title{
Humoral Immune Response of Immunized Sows with Recombinant Proteins of Enterotoxigenic Escherichia coli
}

\author{
Daniele Araujo Pereira1, Caio Abércioda Silva2, Mario Augusto Ono³, Odilon Vidotto1, \\ Marilda Carlos Vidotto ${ }^{{ }^{*}}$ \\ ${ }^{1}$ Depto de Medicina Veterinária Preventiva, Universidade Estadual de Londrina, Londrina, Brazil \\ ${ }^{2}$ Depto de Zootecnia, Universidade Estadual de Londrina, Londrina, Brazil \\ ${ }^{3}$ Depto Ciências Patológicas, Universidade Estadual de Londrina, Londrina, Brazil \\ Email: macarlos@uel.br
}

Received 20 January 2015; accepted 6 February 2015; published 10 February 2015

Copyright (C) 2015 by authors and Scientific Research Publishing Inc.

This work is licensed under the Creative Commons Attribution International License (CC BY). http://creativecommons. org/licenses/by/4.0/

(c) (i) Open Access

\begin{abstract}
Enteric disorders in pigs are related to the fimbriae F4 (K88), F5 (K99), F6 (987P), F41 and F18 of enterotoxigenic Escherichia coli (ETEC). Immunization of sows with adhesins is important to stimulate the production of antibodies and the consequent transfer of these to the piglets via colostrum to prevent diarrhea during the neonate period and after weaning. The objective of this study was to evaluate the immune response of the sows immunized with recombinant ETEC proteins (F4, F5, F6, F18 and F41). The immune response of the sows immunized with the recombinant proteins was compared with a commercial vaccine containing ETEC bacterins. The study was performed on a commercial farm and included nine pregnant sows divided into three groups: G1 was vaccinated with recombinant proteins $(n=3)$; $G 2$ was vaccinated with the commercial vaccine ( $n=3)$; and G3 was vaccinated with sterile buffered saline $(P B S)(n=3)$. All the sows were fed a balanced diet without antibiotics and water ad libitum. The recombinant fimbriae stimulated the specific humoral immune response of the immunized sows. There was a statistically significant increase in the levels of antibodies to the fimbriae F4 (K88), F5 (K99), F6 (987P) and F18 in the sows vaccinated with the recombinant proteins compared with the control group. The colostrum IgG titers for all fimbriae in all the immunized sows were significantly increased compared to the control group. Additionally, all the piglets exhibited significantly increased antibody levels relative to all fimbriae when compared with those in the unimmunized control group, demonstrating successful antibody transfer via colostrum of the sows to the piglets.
\end{abstract}

\section{Keywords}

Humoral Immune Response, ETEC, Recombinant Fimbriae F4, F5, F6, F18, F41

\footnotetext{
${ }^{*}$ Corresponding author.

How to cite this paper: Pereira, D.A., Silva, C.A., Ono, M.A., Vidotto, O. and Vidotto, M.C. (2015) Humoral Immune Response of Immunized Sows with Recombinant Proteins of Enterotoxigenic Escherichia coli. World Journal of Vaccines, 5, 6068. http://dx.doi.org/10.4236/wjv.2015.51008
} 


\section{Introduction}

Enterotoxigenic Escherichia coli (ETEC) strains remain an important cause of diarrheal disease in newborn and weaned piglets [1]-[3]. ETEC strains harbor one or more fimbrial adhesins that are important virulence factors because they allow the bacteria to bind to specific receptors on small intestine enterocytes, resulting in colonization and subsequently the secretion of enterotoxins. The enterotoxins can be heat-labile enterotoxins (LT-1 and LT-2) and/or heat-stable enterotoxins (STa and STb), which induce a severe watery diarrhea by disrupting the water and electrolyte balance in the intestine [4] [5].

Five types of fimbriae are associated with the ETEC strains involved in diarrhea in pigs: F4 (K88); F5 (K99); F6 (987P); F7 (F41); and F18 [5]-[7]. Among these, F4 fimbriae are most frequently found in the type of ETEC that causes diarrhea and mortalityin newborn, suckling and newly weaned piglets, whereas F5, F6 and F41 fimbriae are associated with neonatal diarrhea, and F18 fimbriae are typically associated with post-weaning diarrhea [5] [8].

The losses caused by ETEC in farms have been minimized through vaccination of the sows before farrowing and the use of prophylactic antibiotics [5]. Despite the fact that the pathogenesis of ETEC diarrhea is well studied and that ETEC are recognized as the leading bacterial cause of diarrhea, there is no effective vaccine available against ETEC diarrhea. Additionally, there has been an increase in the incidence of outbreaks of severe $E$. coli-associated diarrhea observed worldwide [5] [9] [10].

In a previous study, we detected a high frequency and several combinations of the fimbrial genes F4, F5, F6, F18, and F41 in E. coli strains isolated from piglets in Paraná State, Brazil [11]. Additionally, multiple virulence genes were found in E. coli isolated from suckling pigs with diarrhea in China [10]. The use of various recombinant fimbriae might be an interesting strategy toward the development of a multivalent vaccine against ETECinduced post-weaning diarrhea.

The present study evaluated the humoral immune response to five recombinant fimbriae of ETEC in pregnant sows through comparison with a commercial vaccine used on farms against ETEC.

\section{Material and Methods}

\subsection{Strains, Vectors, Chemicals}

The E. coli reference K99+ ETEC B41 strain was used to amplify fanC and fim41 genes, which encode K99 and F41 fimbriae subunits, respectively. ETEC wild strains S2 (F4+), S33 (F6+) and S25 (F18+) were isolated from piglets with diarrhea in Paraná State (Vidotto et al. 2009) and they were used to amplify the faeG. fasA and fedF genes, respectively. The $E$. coli host strain BL21 (DE3) was used to produce the recombinant proteins. All the chemical reagents were obtained from Sigma Chemical Co. (St. Louis, MO, USA).

\subsection{Induction and Purification of the Recombinant Proteins}

The genes encoding the fimbriae F4, F5, F6, and F41 were cloned into the expression vector pET102/D-TOPO (Invitrogen Life Technologies, Sao Paulo, Brazil); the gene encoding the fimbriae F18 was cloned into pETTEV, plasmid pET28a (Novagen, Cambridge MA, USA), modified with TEV protease site (from Laboratory Nacional de Biociências, LNBio, Campinas-SP) (unpublished data). The primers were designed based on sequence obtained from GenBank database: F4 (M29376); F5 (M35282); F6 (M35257); F18 (DQ995282) and F41 (X14354).

The E. coli BL21 (DE3) strain was transformed with the recombinant plasmids using thermal shock. The recombinant proteins were obtained after the induction of the recombinant bacteria E. coli BL21 (DE3 Star) that contained the recombinant plasmids with each fimbria.

The recombinant BL21 strains were grown to an $\mathrm{OD}_{600 \mathrm{~nm}}$ of 0 . 7. IPTG (isopropyl-1- $\beta$-D-thiogalactopyranoside) (Invitrogen Life Technologies, Sao Paulo, Brazil) was added to a concentration of $1 \mathrm{mM}$. The cells were collected using centrifugation, and the expression was obtained in insoluble fractions on 12\% SDS-PAGE gels. Additionally, we used auto-induction with lactose to induce the fimbriae F4, F5, F6, F18 and F41, as described by Deacon et al. [12], with slight modifications. Briefly, a seed culture of the recombinant BL21 (DE3) strains were grown overnight $\left(37^{\circ} \mathrm{C}\right)$ to saturation in LB medium. Aliquots of $0.1 \mathrm{~mL}$ of seed culture were inoculated in super brothauto-induction medium (SB auto) with $0.4 \%$ lactose and were grown for $18 \mathrm{~h}$ at $37^{\circ} \mathrm{C}$ with shaking at $250 \mathrm{rpm}$. 
The proteins were expressed and merged to the tail of poly-Histidine (6xHis tag) to facilitate their purification on a column containing resin-bound nickel (Ni-NTA Qiagen ${ }^{\mathrm{TM}}$ ). The cells were collected by centrifugation, incubated with lyse buffer, and the recombinant fimbriaewere purified in denaturant conditions according to the manufacturer instructions (QiagenInc, Valencia, CA, USA). The purified fimbriae were measured using the Bradford method, analysed on SDS-PAGE 12\% and used in the ELISA test.

Additionally, the recombinant fimbriae were purified to a crude extract to be used in the vaccine. The bacteria induced with lactose were collected using centrifugation and incubated in buffer $(0.1 \mathrm{M}$ Tris, $\mathrm{pH}$ 7.0; $1 \mathrm{~m}$ MEDTA; $1 \mathrm{mg} / \mathrm{mL}$ of lysozyme) for $1 \mathrm{~h}$ at room temperature. Then, the cells were frozen and thawed, and the cell lysate was sonicated on ice with three 5-second pulses at high intensity; this step was repeated three times. The pellet containing the recombinant protein crude extract was washed with buffer ( $0.1 \mathrm{M}$ Tris, $\mathrm{pH}$ 8.0; $1.5 \mathrm{M}$ $\mathrm{NaCl} ; 20 \mathrm{mM}$ EDTA and 2\% Triton X-100) and incubated for one $\mathrm{h}$ at room temperature. The pellet was suspended in buffer (50 mMTris, $\mathrm{pH}$ 8.0), and the protein quantification was carried out according to the Bradford method. To assess the degree of purity of the recombinant fimbriae, the fimbriae were analyzed on a $12 \%$ SDSPAGE gel stained with Coomassie brilliant blue.

\subsection{Preparation of the Vaccines}

The mixture containing $100 \mu \mathrm{g}$ of each recombinant fimbria (F4, F5, F6, F18 and F41) from the crude extract, combined with $2 \mathrm{mg} / \mathrm{mL}$ of aluminum hydroxide adjuvant, $0.02 \%$ thimerosal, and PBS to $2 \mathrm{~mL}$, was used as the vaccine candidate. The sows were immunized with the candidate vaccine on the same day of preparation.

The commercial ETEC vaccine used in this study was manufactured by Veterinary Vaccine Company Novartis, containing a mixture of equal volumes of the four inactivated ETEC fimbrial structures: F4 (K88); F5 (K99); F6 (986P); and F41; but not F18.

\subsection{Experimental Animals and Immunization}

This study was performed on a commercial farm; the sows were kept in the same maternity leave room under equivalent temperature and handling conditions. The sows were fed with a commercially available, balanced sow diet without antibiotics or other growth promoters and water ad libitum. After birth, all the newborn piglets were fostered with their dam for a maximum of 21 days. Food and water were provided ad libitum. The piglets were observed on a daily basis for possible clinical manifestations and the incidence of diarrhea.

Nine pregnant sows of same commercial breed, with approximately 85 days of gestation and the same parity order $\left(3^{\text {rd }}\right)$, were divided into three groups: group one $(\mathrm{G} 1)$ was vaccinated with the recombinant proteins $(\mathrm{n}=3)$; the second group (G2) was vaccinated with the commercial vaccine $(n=3)$; and the third (G3) group was inoculated with sterile buffered saline (PBS) $(n=3)$. The pregnant sows were intramuscularly (IM) immunized with the vaccines at 4 and 2 weeks before farrowing.

After the day of farrowing, four piglets from each sow were selected, resulting in a total of 12 piglets per group; these piglets were marked with rings. All the animals were analyzed to determine the titer of anti-protein recombinant antibodies in their serum.

This study was approved by the Ethics Committee on the use of animals (241/2012).

\subsection{Sample Collection and Evaluation of Humoral Immune Responses Measured Using ELISA}

The blood samples were collected from the sows at day 0 (four weeks before farrowing), day 14 (two weeks before farrowing) and day 28 (on the day of farrowing). The colostrum samples were collected from the sows on the day of farrowing. Additionally, blood samples were collected from the piglets from the cranial vena cava on their seventh day of life.

The humoral immune response was evaluated by an indirect ELISA using the purified recombinant fimbriae K88, K99, F6, F18 and F41. Flat bottom microtiter polystyrene plates (Costar Corporation, Corning, NY, USA) were coated with recombinant antigens in $0.1 \mathrm{M}$ buffer carbonate/bicarbonate, $\mathrm{pH}$ 9.6. After washing with 0.05\% PBS-Tween, 5\% PBS milk was added, followed by incubation for $1 \mathrm{~h}$ at room temperature; the antigens were then washed with PBS-T. Then, the serum samples, previously adsorbed with E. coli BL21, were diluted 1:100 in $1 \%$ PBS skimmilk, and added and incubated for $1 \mathrm{~h}$ at $37^{\circ} \mathrm{C}$. The plates were washed with PBS-T, and 
anti-pig IgG peroxidase conjugate (Sigma, St Louis, MO, USA) was added, followed by incubation for $1 \mathrm{~h}$ at room temperature. After washing with PBS-T, substrate-chromogen $\left(\mathrm{H}_{2} \mathrm{O}_{2} / \mathrm{TMBZ}\right.$-tetramethylbenzidine, Sig$\mathrm{ma}^{\mathrm{TM}}$ ) was added. The reaction was stopped by the addition of $1 \mathrm{~N} \mathrm{H}_{2} \mathrm{SO}_{4}$. The absorbance at $450 \mathrm{~nm}$ was measured in a Microplate Reader.

The levels of IgG in serum samples were expressed as OD at $450 \mathrm{~nm}$ and the increase of IgG levels after immunization was expressed as the ratio of OD post-vaccination serum/OD pre-immunization serum.

\subsection{SDS-PAGE and Western Blotting}

The recombinant proteins crude extracts were separated on a 12\% SDS-PAGE. The proteins were electrotransferred to a nitrocellulose membrane. The membrane was blocked in a blocking solution $\left(\mathrm{Na}_{2} \mathrm{HPO}_{4} 7 \mathrm{mM}\right.$, $\mathrm{NaH}_{2} \mathrm{PO}_{4} 3 \mathrm{mM}, \mathrm{NaCl} 140 \mathrm{mM}$ and dried skimmed milk 5\%) for $1 \mathrm{~h}$ at room temperature and after three washed in PBS-T (PBS + 0.1\% Tween 20) for $10 \mathrm{~min}$. After washing, strips of nitrocellulose membrane were incubated with a pool of sera from immunized animals for $1 \mathrm{~h}$. After washing, strips were incubated for $1 \mathrm{~h}$ at room temperature with peroxidase-labeled anti-IgG antibody (diluted 1:10,000 in washing buffer). The membranes were washed, and rfimbriae was detected via incubation with substrate/chromogen solution. Protein molecular mass markers (Rainbow ${ }^{\mathrm{TM}}$ colored, Amersham Life Science) were used as standards.

\subsection{Statistical Analysis}

The data were analyzed by Kruskal-Wallis and Dunn's tests, and the difference was considered significant when $\mathrm{P} \leq 0.06$.

\section{Results}

\subsection{Purification of the Recombinant Fimbriae}

Figure 1(a) shows the induction and the degree of purity of the recombinant proteins crude extracts used in the immunizations.

The auto-induction with the lactose protocol showed good results for the recombinant fimbriae production in the simple batch cultivations. E. coli BL21 (DE3)-RP exhibited the highest quantity with $0.4 \%$ (w/v) lactose, an induction time of 16 to $18 \mathrm{~h}$, and an induction temperature of $37^{\circ} \mathrm{C}$ (Figure 1(a)). Because the recombinant fimbriae were recovered from the inclusion bodies and were insoluble, they were purified with Triton X-100 wash as a total antigen. The proteins remained stable under storage conditions at $-20^{\circ} \mathrm{C}$, and they can be stored for long-term use.

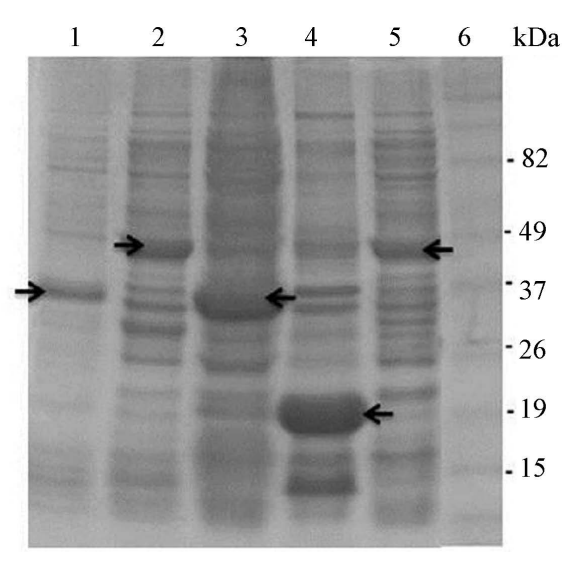

(a)

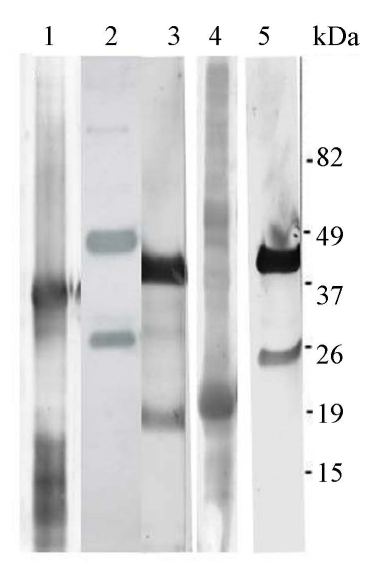

(b)

Figure 1. Expression and purification of recombinant fimbriae (a) SDSPAGE stained with Coomassie brilliant blue of the recombinant proteins crude extracts included in the vaccine. Lane 1-F18 (36 kDa), 2-K88 (46 kDa), 3K99 (40 kDa), 4—987 (20 kDa), 5—F41 (45 kDa), 6—-molecular mass kDa; (b) Western blotting of rfimbriae with polyclonal serum from immunized sows. 


\subsection{Immune Responses of the Vaccinated Sows and Passive Immunity of Their Piglets}

The serum IgG levels against all the fimbrial antigens in the sows are presented in Figure 2 and Figure 3, and

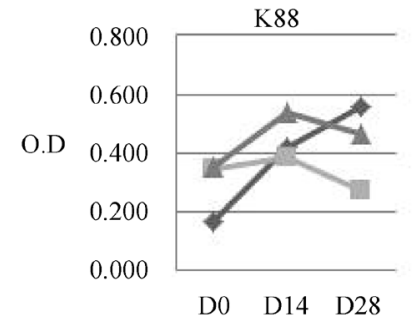

(a)

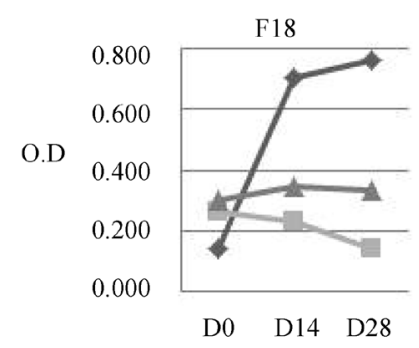

(c)

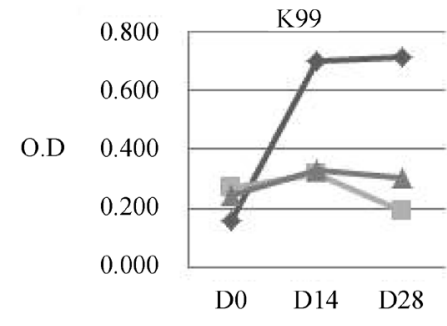

(b)

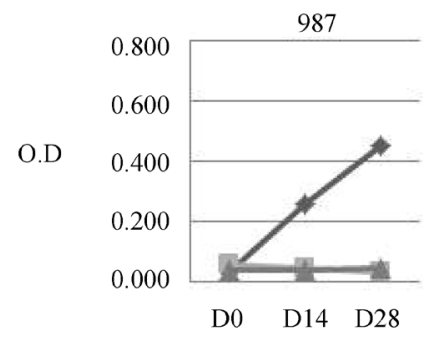

(d)

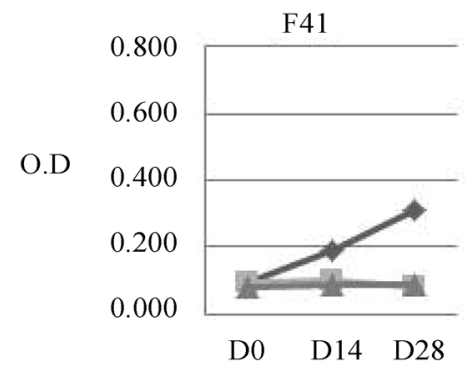

(e)

Figure 2. Levels of IgG against recombinant fimbria (K88, K99, F18, 987 and F14) in immunized sows evaluated by ELISA in days 0 (first immunization), 14 (second immunization) and 28 (farrowing).

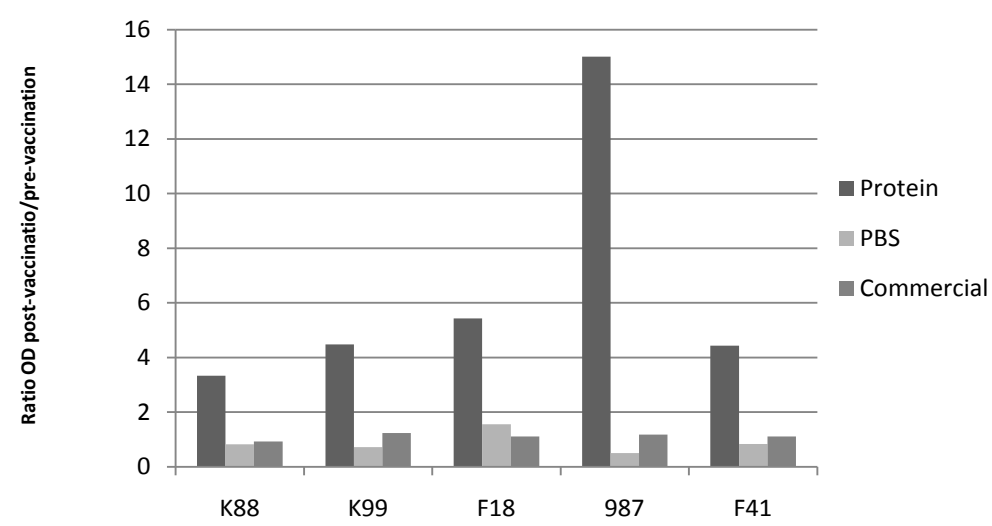

Figure 3. Increase in IgG levels in serum of sows immunized with recombinant fimbriae (Protein), commercial vaccine (Commercial) and unvaccinated (PBS), evaluated by ELISA. The result is expressed as the ratio of OD postvaccination serum/OD pre-vaccination serum. 
the colostrum IgG levels in the sows are shown in Figure 4. The pregnant sows immunized with the recombinant proteins of ETEC presented higher levels of specific antibodies to each fimbria than those of the control group (Figure 2). All the sows showed low levels of antibodies before the first vaccination. All the sows from the control group maintained low levels of IgG (Figure 2). The sows IgG responses were significant higher for the fimbriae K88 ( $p=0.06)$, K99 ( $=0.03)$, F18 ( $=0.05)$, and $987(p=0.02)$ than control group; however, for fimbria F41 the difference to control group was not significant $(\mathrm{p}=0.08)$.

The increase in the antibody levels for fimbriae F41, 987, F18, K88 and K99 is shown in Figure 3, which compares all the antigens analyzed with the three groups tested. The IgG levels increased significantly for the fimbriae K88, K99, F18 and 987 in the group vaccinated with recombinant proteins compared to the unvaccinated control group (PBS). The animals inoculated with the commercial vaccine showed no significant differences with any fimbria in relation to the control group.

The colostrum IgG levels for all the individual antigens in all the vaccinated groups of sows significantly increased compared to those in the non-vaccinated sow group $(\mathrm{p} \leq 0.05)$ (Figure 4$)$.

The levels of specific IgG in the piglets' serum were significantly higher against the fimbriae K88 $(p=0.06)$, K99 ( $p=0.05)$, F41 ( $=0.03)$, F18 $(p=0.06)$, and $987(p=0.02)$ in the recombinant protein vaccine group compared to the control group (Figure 5).

Western blotting analysis showed that sera from immunized sows reacted with the all recombinant proteins crude extracts used in the immunizations (Figure 1(b)).

Diarrhea was not observed in the piglets examined, and there was a mortality rate of $5.5 \%$ in the piglets, but the cause of death was crushing.

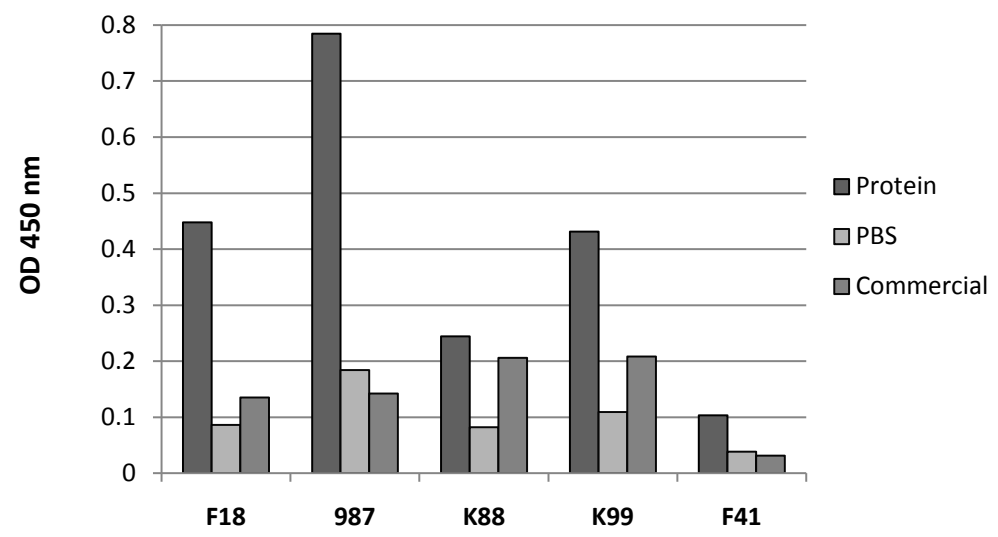

Figure 4. Levels of IgG in the colostrum of sows immunized with the recombinant fimbriae, commercial vaccine and unvaccinated (PBS), evaluated by ELISA.

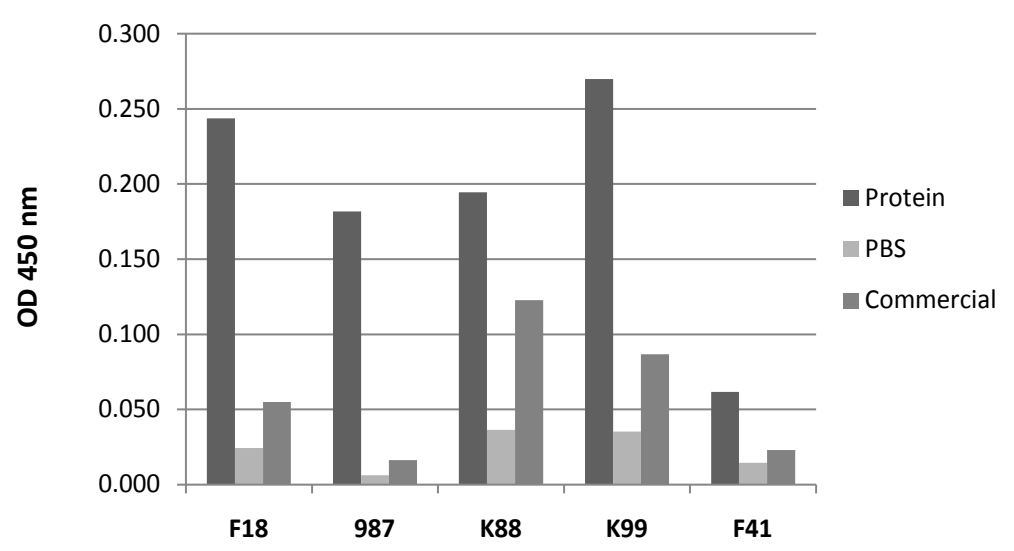

Figure 5. Levels of IgG against recombinant fimbria (F18, 987, K88, K99 and F41) evaluated by ELISA in serum samples of piglets. 


\section{Discussion}

The immunization of sows with ETEC fimbriae is important for the production of specific antibodies and for preventing the colonization of bacteria in the small intestine [13]. Inactivated ETEC whole-cell bacterins or purified ETEC fimbrial subunit vaccines are currently used in the veterinary field. However, some of these vaccines are not very effective, particularly in protecting against post-weaning diarrhea [1].

In this study, sows immunized with five recombinant proteins (rK88, rK99, r987P, rF41, and rF18) showed a higher humoral immune response than sows immunized with commercial vaccine and the unvaccinated control group.

The recombinant fimbriae were recovered from the inclusion bodies using a buffered solution and were purified as total antigen with the Triton X100 procedure. A simple purification process for the recombinant proteins is important for commercial-scale production. The genetic construct included an N-terminal histidine tag sequence that facilitated the recovery, purification, and proper refolding of the vaccine candidate by affinity chromatography; however, this is a high-cost procedure.

Additionally, the cost and composition of the culture media are critical for the commercial-scale production of recombinant proteins in E. coli. The recombinant fimbriae were produced with the use of lactose instead of IPTG for induction. Generally, the recombinant protein is expressed by bacteria via induction with IPTG, which is a good inducer and commonly used in molecular biology; however, it is costly. Lactose is a natural substrate of the bacterial enzyme that is controlled by the lac operon, which is natively induced. Lactose is a low-cost, harmless and avirulent compound [12] [14].

The use of fusion protein was an interesting strategy towards the development of a multivalent vaccine against ETEC-induced post-weaning diarrhea. Osek et al. (1995) [15] tested eight different vaccines in the sows that contained different fimbriae and adjuvants and obtained better results with the vaccine that contained purified K88, K99, 987 and enterotoxin LT. In the present study, sows immunized with recombinant proteins showed the best humoral responses against fimbriae K88, K99, 987 and F18. The results were significant for the fimbria K88, K99, F18, 987 and F41 in the serum of the piglets.

The intramuscular immunizations of pigs with a tripartite FaeG-FedF-LT fusion protein resulted in the induction of IgA antibodies in the serum, inhibition of adherence of F4 and F18 and protection against clinical signs after an F4+ ETEC infection [16]. Similarly, in this study a significant serum antibody response of the sows for the recombinant vaccine with multi-epitopes containing F18; there were also high levels of IgG against F18 in the serum of the piglets.

A vaccine produced with the fimbriae of E. coli: F4ab (K88ab) + F4ac (K88ac) + F5 (K99) + F6 (987P) + LT toxoid was tested in challenge experiments, and all the vaccinated sows showed a rise in seric antibody titers before farrowing [17].

Hur and Lee (2012) [18] did a comparative evaluation of a novel live vaccine candidate expressing ETEC fimbriae and a commercial ETEC vaccine. The E. coli K88ab, K88ac, K99, FasA and F41 fimbrial genes were individually inserted into an expression/secretion plasmid, which were subsequently transfected into attenuated Salmonella and used as a vaccine. Similar to our results, the DNA vaccine with the multi-epitopes exhibited significantly increased antibody levels relative to the specific antigens in all the vaccinated sows and piglets when compared to those in the unvaccinated control group.

The fimbriae 987 and K99 were used in vaccines in the sows [19]. The piglets, after consuming colostrum, reported a lower incidence of diarrhea and a greater weight gain compared to the unvaccinated group after the challenge. This work resulted in an increase in the serum titers of the sows to fimbriae 987 and K99.

The piglets can be effectively protected through lactogenic methods from pregnant sows immunized in the neonatal period, but it is believed that this protection disappears at weaning [8]. The results of this study show the importance of immunizing the sows and the consequent transfer of antibodies to the piglets during the neonate period. The piglets that received colostrum from sows immunized with the recombinant fimbriae showed higher levels of antibodies against fimbriae K88, K99, 987, F18 and F41 than piglets from sows of unvaccinated and commercial vaccine groups.

\section{Conclusion}

The ETEC recombinant fimbriae stimulated the humoral immune response of the pregnant sows that were vaccinated. There was a statistically significant increase in the levels of antibodies to the fimbriae F4 (K88), F5 
(K99), F6 (987P) and F18 compared to the control group. The piglets showed significantly higher levels of antibodies against fimbriae K88, K99, 987, F18, and F41 in relation to the control group, indicating transfer of antibodies via the colostrum.

\section{Acknowledgements}

This work was supported by the "Conselho Nacional de Desenvolvimento Científico e Tecnológico" (CNPq).

\section{Competing Interests}

The authors declare that they have no competing interests.

\section{Authors' Contributions}

All authors contributed to the organization and preparation of the manuscript. All authors approved the final version of the manuscript.

\section{References}

[1] Nagy, B. and Fekete, P.Z. (2005) Enterotoxigenic Escherichia coli in Veterinary Medicine. International Journal of Medical Microbiology, 295, 443-454. http://dx.doi.org/10.1016/j.ijmm.2005.07.003

[2] Almeida, F.S., Rigobelo, E.C., Marin, J.M., Maluta, R.P. and Ávila, F.A. (2007) Diarreia suína: Estudo da etiologia, virulência e resistência a antimicrobianos de agentes isolados em leitões na região de Ribeirão Preto-SP, Brasil. Brasil. Archives Veterinária, Jaboticabal, Vol. 23, 151-157.

[3] Mores, N. and Moreno, A.M. (2007) Neonatal Colibacillosis. In: Sobestiansky, J. and Barcello, D.E.S.N., Eds., Swine Diseases, 2nd Edition, Goiânia, Canon Editorial, 110-114.

[4] Gyles, C.L. (1994) Escherichia coli Enterotoxins. In: Gyles, C.L., Ed., Escherichia coli in Domestic Animals and Humans, CAB International, Wallingford, Oxon, UK, 337.

[5] Fairbrother, J.M., Nadeau, E. and Gyles, C.L. (2005) E. coli in Postweaning Diarrhea in Pigs: An Update on Bacterial Types, Pathogenesis, and Prevention Strategies. Animal Health Research Review, 6, 17-39. http://dx.doi.org/10.1079/AHR2005105

[6] Wilson, R.A. and Francis, D.H. (1986) Fimbriae and Enterotoxins Associated with Escherichia coli Serogroups Isolated from Pigs with Colibacillosis. American Journal of Veterinary Research, 47, 213-217.

[7] Rippinger, P., Bertschinger. H.U., Imberechts, H., Nagy, B., Sorg, I., Stamm, M., Wild, P. and Wittig, W. (1995) Designations F18ab and F18ac for the Related Fimbrial Types F107, 2134P and 8813 of Escherichia coli Isolated from Porcine Postweaning Diarrhoea and from Oedema Disease. Veterinary Microbiology, 45, 281-295. http://dx.doi.org/10.1016/0378-1135(94)00141-I

[8] Melkebeek, V., Goddeeris, B.M. and Cox, E. (2013) ETEC Vaccination in Pigs. Veterinary Immunology and Immunopathology, 152, 37-42. http://dx.doi.org/10.1016/j.vetimm.2012.09.024

[9] Moredo, F.A., Cappuccio, J.A., Insarralde, L., Perfumo, C.J., Quiroga, M.A. and Leotta, G.A. (2012) Genotypic Characterization of Toxigenic Escherichia coli Isolated from Pigs with Postweaning Diarrhea (PWD) and Edema Disease (ED). Revista Argentina de Microbiologia, 44, 85-88.

[10] Liu, W.X., Yuan, C.W., Meng, X.Q., Du, Y.C., Gao, R.Z., Tang, J. and Shi, D.F. (2014) Frequency of Virulence Factors in Escherichia coli Isolated from Suckling Pigs with Diarrhoea in China. The Veterinary Journal, 199, 286-289. http://dx.doi.org/10.1016/j.tvjl.2013.11.019

[11] Vidotto, M.C., Lima, B.C.S., Fritzen, J.T.T., Freitas, J.C.D., Venancio, E.J. and Ono, M.A. (2009) Prevalence of Virulence Genes in Escherichia coli Isolated from Piglets with Diarrhea in the Parana, South Brazil. Brazilian Journal of Microbiology, 44, 515-517. http://dx.doi.org/10.1590/S1517-83822013000200030

[12] Deacon, S.E., Roach, P.C.J., Postis, V.L.G. , Wright, G.S.A., Xia, X., Phillips, S.E.V., Knox, J.P., Henderson, P.J.F., Mcpherson, M.J. and Baldwin, S.A. (2008) Reliable Scale-Up of Membrane Protein Over-Expression by Bacterial Auto-Induction: From Microwell Plates to Pilot Scale Fermentations. Molecular Membrane Biology, 25, 588-598. http://dx.doi.org/10.1080/09687680802511774

[13] Haesebrouck, F., Pasmans, F., Chiers, K., Maes, D., Ducatelle, R. and Decostere, A. (2004) Efficacy of Vaccines against Bacterial Diseases in Swine: What Can We Expect. Veterinary Microbiology, 100, 255-268. http://dx.doi.org/10.1016/j.vetmic.2004.03.002

[14] Donovan, R.S., Robinson, C.W. and Glick, B.R. (1996) Review: Optimizing Inducer and Culture Conditions for Ex- 
pression of Foreign Proteins under the Control of the lac Promoter. Journal Industry Microbiological, 16, 145-154. http://dx.doi.org/10.1007/BF01569997

[15] Osek, J., Truszcyski, M., Tarasiuk, K. and Pejsak, Z. (1995) Evaluation of Different Vaccines to Control of Pig Colibacillosis under Large-Scale Farm Conditions. Comparative Immunology, Microbiology and Infectious Diseases, 18, 18. http://dx.doi.org/10.1016/0147-9571(94)00016-N

[16] Ruan, X., Liu, D., Casey, T.A. and Zhang, W. (2011) The Tripartite Fusion, FaeG-FedF-LT ${ }_{192}$ A2:B, of Enterotoxigenic Escherichia coli (ETEC) Elicits Antibodies That Neutralize Cholera Toxin, Inhibit Adherence of K88 (F4) and F18 Fimbriae, and Protect Pigs against K88ac/Heat-Labile Toxin Infection. Clinical Vaccine Immunology, 18, 1593-1599. http://dx.doi.org/10.1128/CVI.05120-11

[17] Riising, H.J., Murmans, M. and Witvliet, M. (2005) Protection against Neonatal Escherichia coli Diarrhea in Pigs by Vaccination of Statements with a New Vaccine That Contains Purified against Enterotoxigenic E. coli Virulence Factors F4ac, F4ab, F5 and F6 Fimbrial Antigens and Heat-Labile E. coli Enterotoxin (LT). Journal of Veterinary Medicine Series B, 52, 296-300. http://dx.doi.org/10.1111/j.1439-0450.2005.00857.x

[18] Hur, J. and Lee, J.H. (2012) Comparative Evaluation of the Vaccine Candidate Expressing against Enterotoxigenic Escherichia coli (ETEC) Adhesions Is Colibacillosis with a Commercial Vaccine Using a Pig Model. Vaccine, 30, 3829-3833. http://dx.doi.org/10.1016/j.vaccine.2012.03.087

[19] Morgan, R.L., Isaacson, R.E., Moon, H.W., Brinton, C.C. and To, C.C. (1978) Immunization of Suckling Pigs against Enterotoxigenic Escherichia coli-Induced Diarrheal Disease by Vaccinating Dams with Purified 987 or K99 pili: Protection Correlates with Pilus Homology of Vaccine and Challenge. Infection and Immunity, 33, 771-777. 
Scientific Research Publishing (SCIRP) is one of the largest Open Access journal publishers. It is currently publishing more than 200 open access, online, peer-reviewed journals covering a wide range of academic disciplines. SCIRP serves the worldwide academic communities and contributes to the progress and application of science with its publication.

Other selected journals from SCIRP are listed as below. Submit your manuscript to us via either submit@scirp.org or Online Submission Portal.
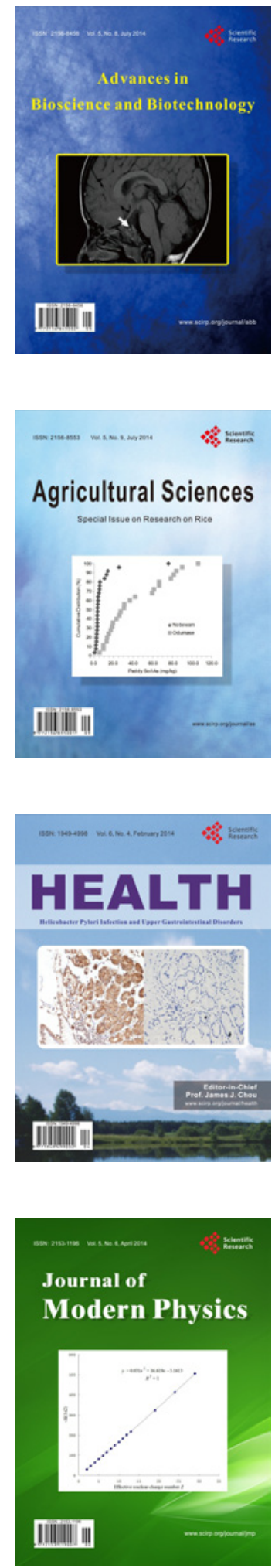
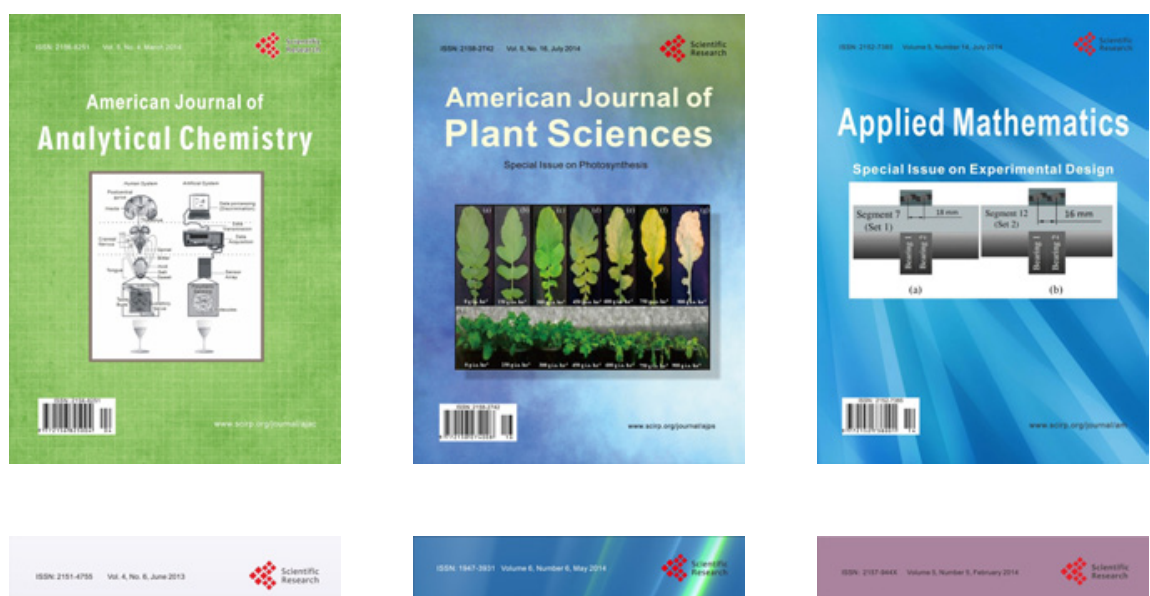

Creative Education
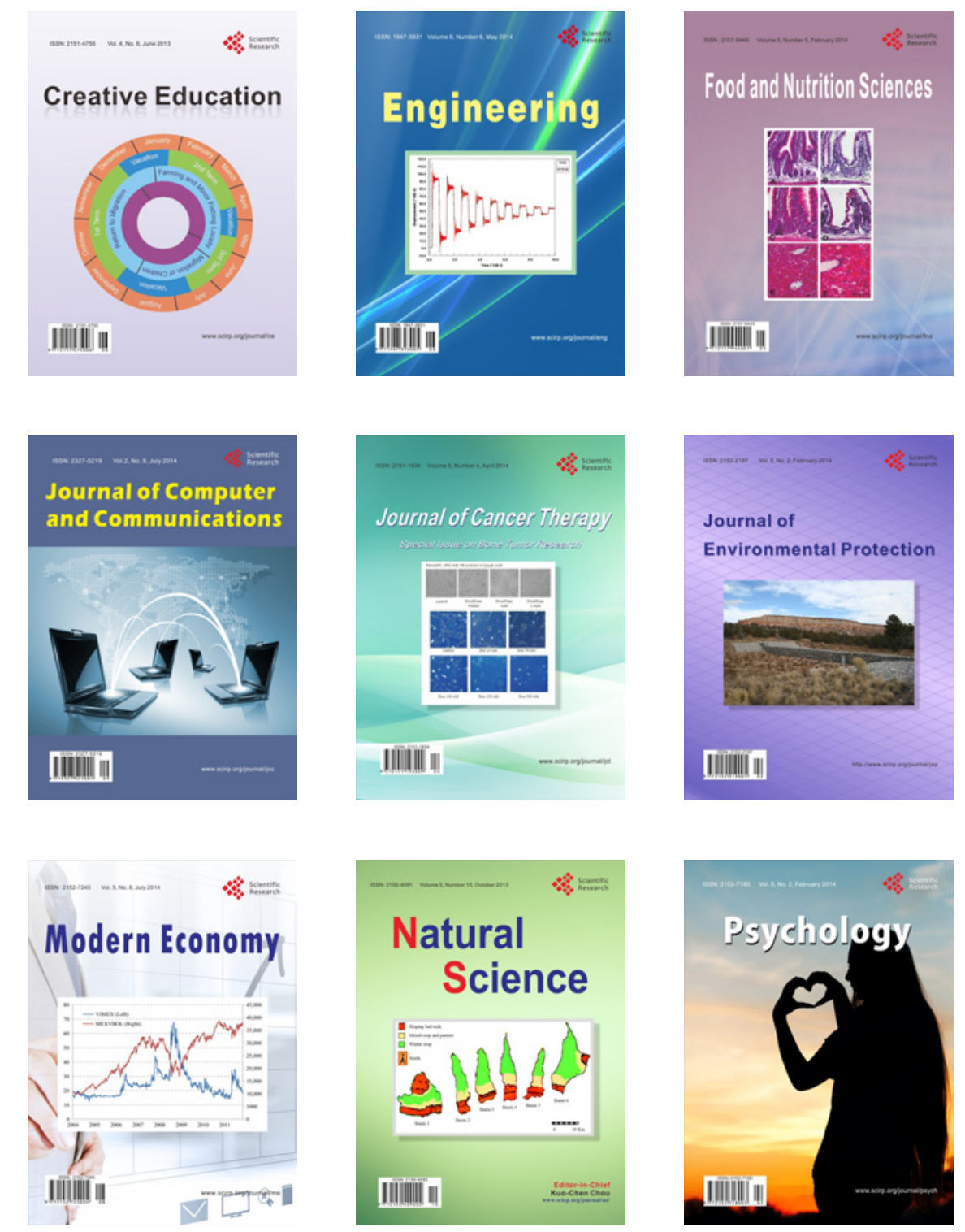